\title{
Investigação sobre o nível de satisfação acadêmica no curso de administração
} CAMEAM-UERN

\author{
Research on the level of academic satisfaction in the CAMEAM-UERN administration course \\ Investigación sobre el nivel de satisfacción académica en el curso de administración CAMEAM- \\ UERN
}

Recebido: 23/12/2020 | Revisado: 25/12/2020 | Aceito: 27/12/2020 | Publicado: 02/01/2021

\author{
Maria Josiany Viana Medeiros \\ ORCID: https://orcid.org/0000-0002-2596-125X \\ Universidade do Estado do Rio Grande do Norte, Brasil \\ E-mail: medeiros.josiany@gmail.com \\ Luma Michelly Soares Rodrigues Macri \\ ORCID: https://orcid.org/0000-0002-3898-6659 \\ Universidade Federal de Campina Grande, Brasil \\ E-mail: luma_michelly@hotmail.com
}

\begin{abstract}
Resumo
O objetivo deste trabalho foi investigar os níveis de satisfação acadêmicas do curso de Administração CAMEAMUERN. A construção de uma pesquisa de satisfação é importante para o desenvolvimento de um ensino de qualidade, junto à concepção dos estudantes que fazem parte do curso e da instituição de estudo, pois são essenciais para a potencialização do crescimento e qualidade de ensino. A presente pesquisa é de caráter qualitativo e quantitativo, de natureza exploratória e descritiva. Para tanto, foi utilizado um questionário com 35 (trinta e cinco) questões sobre a satisfação dos discentes referentes aos vários aspectos relacionados à vida acadêmica, onde atribuíram valores em uma escala de 1 (um) à 5 (cinco) para afirmar entre nada e totalmente satisfeito, respectivamente, e foi aplicado com o universo de 103 (cento e três) alunos do $4^{\circ}$ (quarto) ao $10^{\circ}$ (décimo) período do curso de Administração do CAMEAM-UERN. Após a coleta de dados foram utilizados gráficos e tabelas para demonstração dos resultados obtidos através da análise estatística, esquematizados em 6 (seis) dimensões relacionadas à satisfação pessoal, com o curso, professores, colegas e ambiente físico da instituição, obtendo um resultado positivo perante a satisfação dos alunos com relação à maioria dos aspectos tratados, e uma possível atenção para melhorias no que correspondem aos dados coletados com os resultados neutros. A análise deste estudo pode ser útil à instituição para condutas a serem tomadas para potencialização do nível de satisfação dos discentes do curso de Administração do CAMEAM-UERN.
\end{abstract}

Palavras-chave: Satisfação; Qualidade de ensino; Curso de administração; Ensino.

\begin{abstract}
The aim of this paper was to investigate the academic satisfaction levels of the CAMEAM-UERN Administration course. The construction of a satisfaction survey is important for the development of quality education, along with the conception of the students who are part of the course and of the study institution, as they are essential for potentialing of growth and quality of education. This research is qualitative and quantitative, exploratory and descriptive in nature. To this end, was used a questionnaire with 35 (thirty five) questions about student satisfaction regarding various aspects related to academic life, where they assigned values on a scale of 1 (one) to 5 (five) to state between nothing and fully satisfied, respectively, and was applied to the universe of 103 (one hundred and three) students from the 4th (fourth) to the 10th (tenth) period of the CAMEAM-UERN Administration course. After data collection, charts and tables were used to demonstrate the results obtained through statistical analysis, outlined in six (6) dimensions, related to personal satisfaction, with the course, teachers, colleagues and the physical environment of the institution, obtaining a positive result towards students satisfaction about most of the aspects addressed, and a possible attention to improvements in the data collected with the neutral results. The analysis of this study may be useful to the institution for actions to be taken to potentialing of satisfaction level of the students of the CAMEAM-UERN Administration course.
\end{abstract}

Keywords: Satisfaction; Education quality; Managment course; Teaching.

\section{Resumen}

El objetivo de este trabajo fue investigar los niveles de satisfacción académica del curso de Administración CAMEAM-UERN. La construcción de una encuesta de satisfacción es importante para el desarrollo de una docencia de calidad, junto con la concepción de los estudiantes que forman parte del curso y la institución de estudio, ya que son fundamentales para potenciar el crecimiento y la calidad de la docencia. Esta investigación es cualitativa y cuantitativa, exploratoria y descriptiva. Para ello se utilizó un cuestionario con 35 (treinta y cinco) preguntas sobre la 
satisfacción de los estudiantes con respecto a los distintos aspectos relacionados con la vida académica, donde asignaron valores en una escala de 1 (uno) a 5 (cinco) para indicar entre nada y totalmente satisfecho, respectivamente, y se aplicó al universo de 103 (ciento tres) alumnos del $4^{\circ}$ (cuarto) al $10^{\circ}$ (décimo) período de la carrera de Administración CAMEAM-UERN. Luego de la recolección de datos, se utilizaron gráficos y tablas para demostrar los resultados obtenidos a través del análisis estadístico, resumidos en 6 (seis) dimensiones relacionadas con la satisfacción personal, con el curso, docentes, colegas y el entorno físico de la institución, obteniendo un resultado positivo antes satisfacción de los estudiantes con la mayoría de los aspectos abordados, y posible atención a mejoras en lo que corresponde a los datos recolectados con los resultados neutrales. El análisis de este estudio puede ser de utilidad para la institución en las conductas a realizar para mejorar el nivel de satisfacción de los estudiantes en el curso de Administración de CAMEAM-UERN.

Palabras clave: Satisfacción; Calidad docente; Curso de administración; Ensenãnza.

\section{Introdução}

As Instituições de Ensino Superior (IES) têm se mostrado importantes no desenvolvimento intelectual e social dos estudantes, oferecendo não somente conhecimento, sejam eles de base teórica ou prática, mas também toda uma experiência de convívio entre discentes, docentes, funcionários e a comunidade em geral, fazendo com que o aluno seja estimulado a essas vivências e a compreensão de todos os processos que as universidades oferecem. Para Nogueira (2004), isso se justifica na produção do conhecimento, na formação de cidadãos com pensamento crítico, de profissionais capazes de articular saberes e se tornarem líderes intelectuais.

O ingresso do estudante no ensino superior demanda uma série de transformações ao longo do tempo, desde a sua escolha quanto à opção de curso superior, até o desempenho acadêmico e futuro profissional dentro da área de atuação. Dessa maneira, o curso de graduação será o seu novo ambiente de formação e responsável pela qualidade de ensino ofertado, sendo este capaz de interferir de forma positiva ou negativa ao longo da sua construção como aluno e profissional, assim como na sua satisfação acadêmica.

Segundo Gusmão (2010, p.27), "o uso da palavra qualidade no contexto educacional remete diretamente aos fins da educação, no sentido absoluto, uma educação de qualidade seria, portanto, uma educação que cumpre com os seus objetivos". A satisfação do aluno está ligada diretamente a qualidade da educação à qual o estudante está inserido, seja ela através da estrutura física das salas de aulas ou didáticas abordadas, sendo eles possíveis fatores fundamentais para que a satisfação do aluno seja atingida de forma positiva ou negativa.

De acordo com Neves e Ramos (2001), no cenário atual, as instituições de ensino superior devem preocupar-se com a manutenção de elevados níveis de satisfação frente aos seus alunos, para tanto, não podem limitar-se a ser simples fornecedoras de conhecimento, necessitando estar atentas para uma contínua adaptação das suas estruturas às transformações ocorridas no ambiente. Nessa perspectiva, diante dos fatores envolvidos, surge o questionamento: Qual o nível de satisfação acadêmica dos discentes do curso de Administração do CAMEAM-UERN?

A motivação para estudo da satisfação acadêmica dos estudantes do curso de Administração parte do pressuposto que esse fator influencia diretamente no desempenho dos estudantes, podendo afetar várias esferas da sua vida acadêmica ao longo do tempo. Diante de tudo isso, o objetivo desse artigo científico é avaliar o nível de satisfação acadêmica dos discentes do curso de Administração do CAMEAM-UERN localizado na cidade de Pau dos Ferros/RN.

\section{Referencial Teórico}

Buscando responder o problema desta pesquisa, o presente estudo aborda a revisão literária, que norteia toda a pesquisa com o embasamento científico, trazendo os pontos sobre o ensino superior no Brasil, na sequência, a graduação de administração no Brasil, qualidade e satisfação no ensino de administração. 


\subsection{Ensino superior no Brasil}

O debate sobre educação superior no Brasil perpassa pela contextualização de seu âmbito local e regional. O Brasil é um país que historicamente sempre enfrentou grande desigualdade social em seu território, pertencente a um continente com os maiores índices de desigualdade em vários aspectos sociais e financeiros, principalmente no acesso à educação. Nesse contexto, as universidades se tornam o principal meio de geração de oportunidades para melhoria de vida e formação de maneira digna do indivíduo enquanto cidadão (Stallivieri, 2006).

Diferentemente do restante da América Latina, que fundou suas primeiras universidades ainda no século XVI, o advento das universidades no Brasil foi tardio, o que agravou ainda mais os problemas da sua já fragilizada sociedade, somente na década de 1930 com a criação de universidades como a USP e A PUC-RJ. Até aquele momento, o ensino superior era retido para escolas superiores, que se voltavam para a formação de médicos e juristas, absolvendo aproximadamente 30 mil estudantes, sem, contudo, realizar qualquer tipo de atividades relacionadas à pesquisa cientifica e sendo acessível somente para classes burguesas (Neves \& Martins, 2014).

O processo de industrialização pós Segunda Guerra Mundial, impulsionou o pensamento de que o Brasil precisava promover maior qualificação à sua sociedade, nesse contexto, em 1960 iniciou-se a campanha de criação das universidades federais em todo território nacional, entretanto, foi feito de maneira desordenada e sem o correto planejamento, levando à criação de várias instituições sem recursos necessários para operar e oferecer o nível de ensino adequado (Stallivieri, 2006, Neves \& Martins, 2014).

Com o advento da reforma universitária, durante o Governo Militar, na década de 60, foi aberta a possibilidade de instituições particulares ofertarem cursos de nível superior, o que ao curto prazo se mostrou benéfico em termos estatísticos, atendendo uma alta demanda que ainda não era atendida pelas instituições públicas (Neves \& Martins, 2014), embora, atualmente, muitos estudiosos questionem a capacidade de ensino-aprendizagem da maioria das instituições privadas, por muitas vezes preocupadas tão somente com a geração de lucro aos seus donos (Silva, 2001).

Segundo dados do Censo da Educação Superior, o Brasil possuía em 2017 cerca de 296 instituições públicas de ensino superior, das quais somente 199 são universidades, e 2152 instituições privadas, ofertando somadas, cerca de 35.380 cursos de graduação (Inep, 2017).

Hoje as Instituições são organizadas com o que chamam de tripé da educação. De acordo com a Constituição Federal de 1988, no seu Art. 207, estabelece que as universidades desenvolverão ações indissociáveis entre ensino, pesquisa e extensão. "As universidades gozam de autonomia didático-científica, administrativa e de gestão financeira e patrimonial, e obedecerão ao princípio de indissociabilidade entre ensino, pesquisa e extensão". A indissociabilidade traz o princípio que deve ser vivido no âmbito das Universidades, fazendo com que exista uma contribuição ainda maior entre o relacionamento das universidades e sociedade, fornecendo assim possibilidades de um conhecimento mútuo.

Com todo o contexto histórico descrito anteriormente do ensino superior no Brasil, é possível seguir com a chegada do curso de graduação em Administração no Brasil, trazendo a história do seu surgimento e todo o seu processo de instalação até os dias atuais.

\subsection{Graduação de Administração no Brasil}

O contexto histórico do surgimento da Administração no Brasil denota uma influência direta com os Estados Unidos, com o crescimento econômico voltado para essa grande potência mundial e com o desenvolvimento de indústrias que proporcionou a necessidade de ensino na área de administração, onde por sua vez a área surgiu com a doutrinação americana. Segundo Nicollini (2003), a influência estrangeira no ensino de Administração torna a se manifestar, de forma mais vigorosa, em função do convênio firmado em 1959 entre os governos brasileiro e norte americano, instituindo o Programa de Ensino de 
Administração Pública e de Empresas. Formando parcerias entre os países para que fosse possível desenvolver o ensino de Administração no Brasil.

No Brasil a criação do curso de Administração passou por dois momentos bastantes influentes em sua criação por volta do início do século XX. O primeiro foi no Governo de Getúlio Vargas em 1930 e o segundo no Governo de Juscelino Kubitschek, um com visão autônoma nacionalista e o outro com visão mais aberta para a economia em caráter internacionalista no ano de 1964. Andrade e Amboni (2004) explicam que duas vertentes surgiram, uma ligada a Administração Pública, com a criação da Escola Brasileira de Administração Pública (EBAP) no Rio de Janeiro no ano de 1952, e dois anos depois a Escola de Administração de Empresas de São Paulo (EAESP), ambas pela Fundação Getúlio Vargas (FGV). O que demonstra a força que a área da administração veio ganhando ao longo do tempo desde o seu início.

A Fundação Getúlio Vargas (FGV) foi de grande importância na implantação do ensino de Administração no Brasil com a criação da EAESP e da EBAP, onde resultou em uma geração de formadores e profissionais na área da administração, formando assim professores para outras unidades de ensino consolidando a expansão do curso, momento esse que se alinhou a expansão dos cursos de administração (Bertero, 2006, Andrade \& Amboni, 2004).

Em 1966 foi consolidado o primeiro currículo mínimo do curso de Administração e permaneceu vigente até 1993 , quando se iniciou a segunda fase de estruturação do curso, que passou por uma reformulação. Para tal surgiram as habilitações específicas para o curso de administração, o que permitiu que cursos com enfoque estritos da atuação profissional fossem ofertados por todo o país (Pinto \& Motter Junior, 2012).

\subsection{Qualidade e Satisfação no ensino da Administração}

Considerando a realidade das Instituições de Ensino Superior (IES), a qualidade e a satisfação estão ligadas diretamente entre si, sejam elas nas instituições públicas como também nas privadas. Por incluir diferentes áreas da experiência acadêmica do estudante, a satisfação é considerada multidimensional (Soares, Vasconcelos \& Almeida, 2002, 153-156). Os níveis de satisfação se abrangem por diversas áreas o que interligam, assim como na qualidade de ensino que por sua vez contribui para a percepção de satisfação do estudante dentro do ambiente acadêmico.

Pennington, Zvonkovic e Wilson (1989, p. 528) destacam que a satisfação pode mudar ao longo de sua trajetória, em razão de a experiência educacional ser vivenciada ou afetada pelas próprias características do indivíduo. A satisfação acadêmica está bastante interligada com a qualidade na área de aprendizagem, fazendo com que exista todo um processo de métodos da Instituição, sendo que esses métodos podem ser grandes fatores que influenciam na satisfação dentro do ambiente de ensino.

A parceria no aprendizado é a ideia predominante, onde o aluno é um parceiro no ensino-aprendizagem e não mais apenas um recebedor de conhecimento. Assim, a sua opinião e satisfação adquirem uma importância muito grande (Souza \& Reinert, 2010). Os alunos, juntos com a unidade de Ensino formam parcerias mútuas para se desenvolverem no ambiente acadêmico, através disso, fatores podem influenciar no grau de satisfação, podendo aumentar ou diminuir esse elemento. Quando a satisfação é existente no meio acadêmico, existe a influência positiva tanto para os alunos (interno) quanto para própria sociedade (externo) e até mesmo futuros alunos, pois a qualidade na Instituição ofertada gera efeitos satisfatórios tanto no seu público interno quanto externo.

Seguindo o pensamento de Alves, Mainardes e Raposo (2010), que tratam a satisfação como um estado capaz de trazer benefícios mútuos a organização e público-alvo, que no caso acadêmico é o discente, o cumprimento da missão de toda instituição universitária perpassa pela capacidade da organização oferecer condições minimamente desejadas para a permanência do discente na atividade acadêmica.

Schreiner (2009) defende que a satisfação do aluno e, por consequência sua retenção, estão intimamente ligadas à 
forma como o aluno valoriza a imagem da instituição. Nesse sentido, o autor nos remete à visão que o aluno terá da instituição ao qual está inserido, suas percepções desse ambiente, da maneira que a mesma também agrega valores para os alunos, todas essas variáveis contribuem para a formação da satisfação ou insatisfação do aluno no âmbito acadêmico.

\section{Metodologia}

O presente estudo se qualifica como de natureza aplicada, pela investigação de uma realidade específica, através de um estudo de caso, baseando-se em uma investigação de abordagem quali-quantitativa de finalidade exploratório e descritivo (Alyrio, 2009, Gil, 2008), que foi realizado através dos discentes do curso de administração da UERN no campus de Pau dos Ferros, RN.

Trata-se de uma pesquisa exploratória (Alyrio, 2009), uma vez que não foi encontrada nenhuma literatura deste assunto na Universidade, campo de realização do estudo. Diante disso, esse estudo pode servir como base para futuras pesquisas. Para Prodanov e Ernani (2013) a pesquisa exploratória "visa a proporcionar maior familiaridade com o problema, tornando-o explícito ou construindo hipóteses sobre ele".

A pesquisa aborda a finalidade descritivo, que tem como característica identificar possíveis relações entre variáveis (GIL, 2002). Desse modo, a pesquisa busca investigar as possíveis variáveis que estão relacionadas com a satisfação dos discentes do curso de administração.

A abordagem utilizada foi a quali-quantitativa, por possuir elementos que necessitam ser tratados de ambas as formas (GIL, 2008). Qualitativa porque busca "[...] descrever a complexidade do problema, analisar a interação de certas variáveis, compreender e classificar processos dinâmicos vividos por grupos sociais e contribuir no processo de mudança de determinado grupo [...]" (Richardson, 2007, p. 80); quantitativo porque caracteriza-se pela quantificação de dados, tanto nas técnicas estatísticas pelas quais as informações são tratadas, quanto nas modalidades de coleta de informações, conforme afirma Richardson (2007).

A pesquisa tomou como base o número dos discentes matriculados no curso de administração da UERN campus de Pau dos Ferros/RN. O curso atualmente conta com 163 matriculados, foi então calculado a amostra com base nesse total para se chegar à porcentagem aceitável da confiabilidade (95\%). Para o cálculo o modelo da plataforma SOLVIS, que desenvolve o cálculo amostral considerando noventa e cinco por cento de confiança e cinco por cento de erro. Como resultado final, baseado no Universo de 163 alunos matriculados, foi considerado para a pesquisa o total de 103 alunos, que permitiram a aplicação do instrumento. Para a aplicação foram escolhidos os alunos do $4^{\circ}$ ao $10^{\circ}$ período, tendo em vista que os discentes já teriam um tempo considerável na instituição, construindo assim o censo da pesquisa.

Quanto à coleta de dados referente ao nível de satisfação acadêmica dos discentes do curso de administração, as perguntas foram adaptadas para atender a pesquisa baseado no estudo de uma tese de mestrado cujo tema é Integração $\mathrm{Na}$ Educação Superior E Satisfação Acadêmica De Estudantes Ingressantes E Concluinte, da autoria de Ana Lúcia Righi Schleich no ano 2006. O questionário foi composto por duas partes. Na primeira, o questionário buscou a caracterização do aluno, onde era possível atribuir os dados como: gênero, idade e a cidade que o discente reside. Na segunda, o questionário traz 35 perguntas que medem o grau de satisfação do aluno sendo que 1 representa "nada satisfeito" e 5 representa "totalmente satisfeito", onde as perguntas abordam as próprias experiências contidas no curso de administração. Foi aplicado nas turmas do $4^{\circ}$ (quarto) ao $10^{\circ}$ (décimo) período, entre os dias 29 e 31 de julho de 2019. 


\section{Resultados e Discussão}

Esse capítulo da pesquisa traz os resultados do estudo sobre o nível de satisfação acadêmica dos alunos no curso de Administração CAMEAM/UERN, demonstrando seus resultados pós análises dos dados coletados, o que fundamenta todo o estudo desenvolvido neste artigo.

Inicialmente, pesquisou-se junto aos alunos qual sua idade, os resultados dessa pesquisa se encontram no Gráfico 1 abaixo. Os dados do gráfico mostram que os estudantes do curso de Administração do CAMEAM/UERN têm em média a sua idade entre 16 a 29 anos que somam $85 \%$ de total dos estudantes do curso, mostrando assim um grande interesse de jovens pelo o curso.

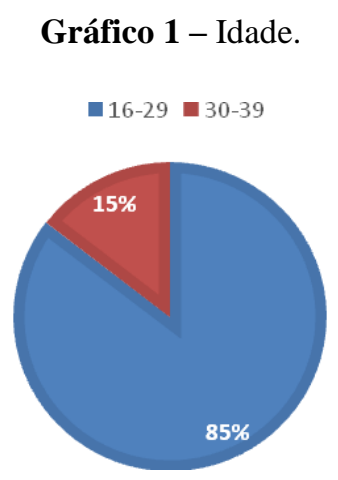

Fonte: coleta de dados (2019).

A pesquisa também buscou dados no que correspondem aos gêneros dos alunos, onde diziam ser do sexo masculino ou feminino. O Gráfico 02 abaixo mostra que 52\% dos alunos que responderam o questionário correspondem ao sexo masculino e $48 \%$ do sexo feminino, sendo em sua maioria masculino, apresentando um perfil com características marcantes da profissão de Administração no cenário profissional, como apontam os dados da pesquisa realizada pelo Conselho Federal de Administração em 2015, revelando que a maioria dos profissionais de administração no Brasil é do sexo masculino, casado e com dependentes, mesmo com o crescimento feminino na profissão que passou de $21 \%$ em 1994 para $34 \%$ em 2015 , o sexo masculino ainda prevalece sobre o feminino. (Conselho Federal De Administração, 2017).

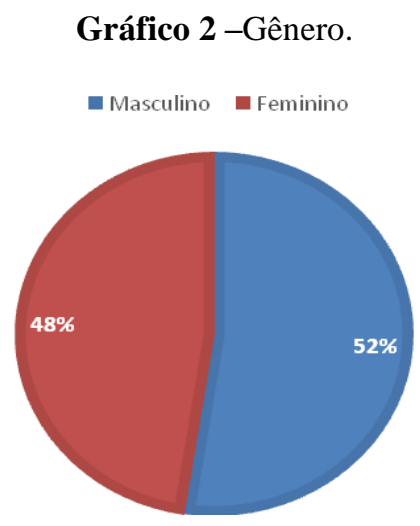

Fonte: Coleta de dados (2019).

Investigou-se quais seriam as cidades onde os estudantes que responderam ao questionário residiam, e os resultados estão apresentados no Gráfico 03, a seguir: 


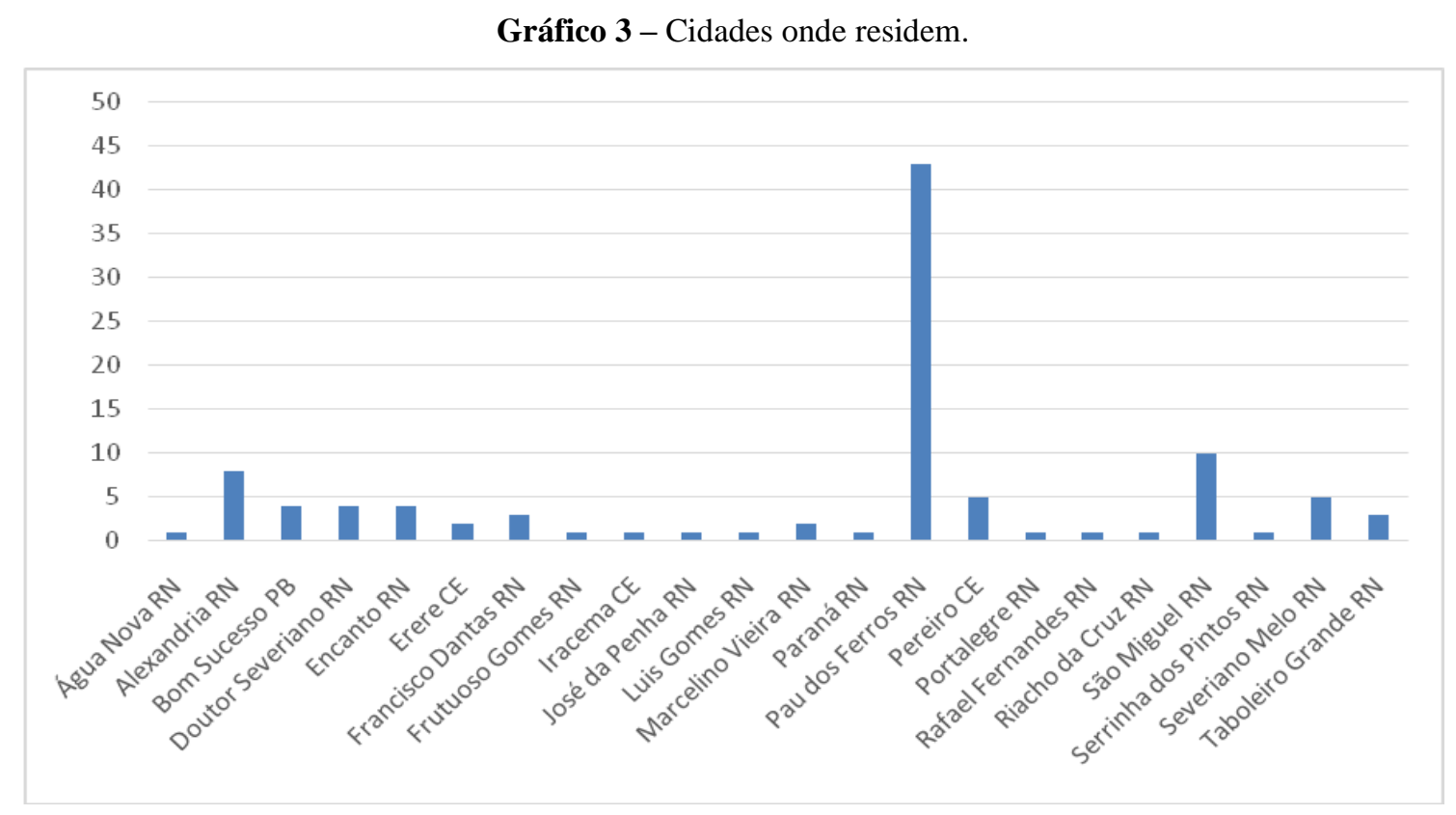

Fonte: Coleta de dados (2019).

A pesquisa revelou que existem alunos do estado do RN, CE e PB, sendo ao todo 22 cidades, logo é visível a grande importância do curso e da Universidade por atender uma região que ultrapassa limites entre estados, e que a maioria reside na cidade da própria Universidade, Pau dos Ferros/RN. Partindo para a análise das dimensões de satisfação abordadas pelo questionário, se pôde organizar os dados obtidos em seis dimensões, envolvendo questões referentes às percepções pessoais de relacionamento, comprometimento individual e condições oferecidas pelo ambiente para o desenvolvimento pessoal e profissional do indivíduo.

\subsection{Relacionamento}

É essencial a parceria, com intuito de germinar o interesse e considerar que os discentes sejam providos de maturidade para que possam ser corresponsáveis em sua própria formação (MASETTO, 1998). Os dados acerca da dimensão relacionamento são apresentados na Tabela 1 abaixo:

Tabela 1 - Relacionamento.

\begin{tabular}{cccccc} 
Variável & $\mathbf{1}$ & $\mathbf{2}$ & $\mathbf{3}$ & $\mathbf{4}$ & $\mathbf{5}$ \\
Relacionamento com professores & $1 \%$ & $2 \%$ & $17 \%$ & $45 \%$ & $36 \%$ \\
Relacionamento com colegas & $1 \%$ & $5 \%$ & $15 \%$ & $35 \%$ & $45 \%$ \\
\hline
\end{tabular}

Fonte: Coleta de dados (2019).

Na Tabela 01 é possível observar o grau de satisfação positivo quanto ao relacionamento dos discentes e docentes, apresentando um percentual significativo de $45 \%$ para a satisfação ligada ao relacionamento com os professores, assim como a satisfação com os colegas de curso. Apenas $1 \%$ de ambas as variáveis apresentou insatisfação, dado esse de grande importância, pois essa interação positiva entre discentes e docentes contribui para um ambiente mais saudável e gera elementos que ajudam a desenvolver na qualidade de ensino aprendizagem.

$\mathrm{Na}$ dimensão de relacionamento não foram observados grandes problemas, considerando que apenas uma pequena parcela apontou para a não satisfação, denotando a existência de uma rede de relacionamentos interpessoais benéficos para o 
indivíduo, sendo, portanto, uma ótima variável de promoção da satisfação, considerando a necessidade humana de relacionarse em harmonia com os demais indivíduos que o rodeiam.

\subsection{Interesse, conhecimento e compromisso}

Em seguida, foi analisada a satisfação referente ao interesse e conhecimento por parte dos professores do curso, abordando a visão dos discentes quanto essas variáveis e mostrando o compromisso da instituição com a qualidade de formação. Os dados coletados acerca da dimensão interesse, conhecimento e compromisso estão dispostos na Tabela 2 :

Tabela 2 - Interesse, conhecimento e compromisso.

\begin{tabular}{cccccc}
\hline Variável & $\mathbf{1}$ & $\mathbf{2}$ & $\mathbf{3}$ & $\mathbf{4}$ & $\mathbf{5}$ \\
Interesse dos professores & $0 \%$ & $3 \%$ & $17 \%$ & $36 \%$ & $45 \%$ \\
Conhecimento dos professores sobre os conteúdos das disciplinas & $1 \%$ & $1 \%$ & $18 \%$ & $50 \%$ & $29 \%$ \\
Compromisso da instituição com a qualidade da minha formação & $3 \%$ & $4 \%$ & $28 \%$ & $39 \%$ & $26 \%$ \\
\hline Fonte: coleta de dados (2019).
\end{tabular}

As variáveis apresentadas, conforme a Tabela 02, demonstram valores expressivos quanto a satisfação dos discentes nesses quesitos, trazendo a visão que os mesmos reconhecem o esforço dos professores para proporcionar a melhoria contínua do processo de ensino-aprendizagem, grande pilar da formação profissional e pessoal dos discentes.

Quanto ao grau de interesse dos professores $45 \%$ afirmaram estar totalmente satisfeitos, acompanhado pelo conhecimento dos professores sobre os conteúdos abordados das disciplinas que alcançou um percentual de $50 \%$ de satisfação. Quanto ao compromisso da instituição com a qualidade da formação, houve uma variação de respostas, e ainda assim $39 \%$ dos respondentes afirmaram estar satisfeitos. Essa informação reflete o comprometimento da instituição com a qualidade da formação, proporcionando um estudo mais amplo do campo de análise enquanto ensino, pesquisa e extensão oferecidos pela IES.

O estudo também abordou variáveis quanto ao Reconhecimento dos professores com o comprometimento dos alunos onde $48 \%$ se disseram satisfeitos com esse reconhecimento, em contrapartida $6 \%$ dos respondentes disseram estar insatisfeitos no quesito da disponibilidade dos professores fora da sala de aula, sendo essa uma lacuna a ser observada para possíveis melhorias e desenvolvimento.

\subsection{Adequação de conteúdo}

Nos pontos que abordam a dimensão relacionada ao nível de satisfação dos conteúdos repassados em sala de aula e a adequação dos mesmos e as atividades aplicadas, se destaca percepção da importância de todo um conjunto, desde o corpo docente atuante e comprometido com um ensino de qualidade, até o material trabalhado com os futuros profissionais da área em estudo como importantes para a garantia, na visão dos respondentes, da melhor capacidade de formação profissional, os dados são mostrados na Tabela 3: 
Tabela 3 - Adequação de conteúdo

\begin{tabular}{cccccc} 
Variável & $\mathbf{1}$ & $\mathbf{2}$ & $\mathbf{3}$ & $\mathbf{4}$ & $\mathbf{5}$ \\
Relevância dos conteúdos da disciplina & $1 \%$ & $4 \%$ & $23 \%$ & $51 \%$ & $20 \%$ \\
Adequação do conteúdo do curso para formação & $2 \%$ & $8 \%$ & $31 \%$ & $44 \%$ & $16 \%$ \\
$\begin{array}{c}\text { Adequação entre tarefas e tempo estabelecido para } \\
\text { entrega }\end{array}$ & $1 \%$ & $7 \%$ & $35 \%$ & $43 \%$ & $15 \%$ \\
\hline
\end{tabular}

Fonte: Coleta de dados (2019).

A relevância dos conteúdos das disciplinas se torna um instrumento importante para se alcançar os objetivos desejados no decorrer da formação acadêmica, assim os alunos do curso de Administração do CAMEAM/UERN responderam estar satisfeitos com $51 \%$ considerando positivamente os conteúdos abordados para a sua formação, $31 \%$ dos respondentes afirmaram uma posição neutra quanto a sua adequação, em contraponto $44 \%$ dos resultados foram satisfatórios. Já quanto ao tempo estabelecido para realização de tarefas, $35 \%$ dos respondentes demonstraram neutralidade, com relatos que poderiam haver melhorias por parte dos professores para a adequação de prazos.

\subsection{Currículo do curso}

Tal constatação coloca em discussão a necessidade da adequação contínua dos conteúdos abordados em sala de aula e o aumento de atividades extensionistas e de campo, tão necessárias ao desenvolvimento pleno das capacidades profissionais de discentes que estão em um curso, voltado para cenários de constantes mudanças, fazendo-se necessário que essas mudanças sejam absorvidas rapidamente pela academia, tal como defendem Pinto e Motter Junior (2012), para a melhor formação do profissional de administração. Assim, os dados acerca da dimensão currículo do curso são apresentados na Tabela 4 logo abaixo:

Tabela 4 - Currículo do curso.

\begin{tabular}{cccccc}
\hline Variável & $\mathbf{1}$ & $\mathbf{2}$ & $\mathbf{3}$ & $\mathbf{4}$ & $\mathbf{5}$ \\
Diversidade de atividades extracurriculares oferecidas & $2 \%$ & $15 \%$ & $49 \%$ & $31 \%$ & $4 \%$ \\
Currículo do curso & $3 \%$ & $10 \%$ & $45 \%$ & $34 \%$ & $9 \%$ \\
\hline
\end{tabular}

Fonte: Coleta de dados (2019).

Quanto à dimensão referente ao desenvolvimento por parte do currículo do curso e diversidade de atividades extracurriculares oferecidas, destacam-se a neutralidade dos respondentes com $49 \%$ e $45 \%$ respectivamente, com um índice de insatisfação de $15 \%$ para as atividades extracurriculares e $10 \%$ para o currículo, onde boa parte relata a desatualização da grade em vigor no curso de Administração do CAMEAM/UERN e as poucas opções existentes de atividades extracurriculares que dificultam o desenvolvimento dos discentes na sua formação.

\subsection{Oportunidade de desenvolvimento}

A dimensão relacionada aos níveis de satisfação dos alunos para as questões de oportunidade e desenvolvimento dentro do curso e instituição. Os dados são apresentados na Tabela 5 abaixo: 
Tabela 5 - Oportunidade de desenvolvimento.

\begin{tabular}{|c|c|c|c|c|c|}
\hline Variável & 1 & 2 & 3 & 4 & 5 \\
\hline Programas e serviços de apoio estudantil oferecidos & $11 \%$ & $19 \%$ & $38 \%$ & $27 \%$ & $5 \%$ \\
\hline Programas de apoio financeiro oferecidos pela instituição & $19 \%$ & $26 \%$ & $35 \%$ & $14 \%$ & $6 \%$ \\
\hline $\begin{array}{l}\text { Oportunidades de desenvolvimento pessoal oferecidas pela } \\
\text { instituição }\end{array}$ & $8 \%$ & $17 \%$ & $37 \%$ & $33 \%$ & $6 \%$ \\
\hline
\end{tabular}

Fonte: Coleta de dados (2019).

Observou-se através dos dados expostos na Tabela 05 que embora exista uma parcialidade quanto aos programas de apoio e serviços estudantis oferecidos, assim como oportunidades de desenvolvimento pessoal, os índices de insatisfação nível 1, mostram números elevados levando em consideração ao nosso universo de pesquisa de 103 alunos, com $11 \%$ e $19 \%$ respectivamente e relatos que esperam por melhorias que incentivem aos alunos a desenvolverem cada vez mais a sua performance quanto profissional e pessoal.

Os dados apresentados denotam a existência de um cenário de pouco suporte financeiro disponível e ofertado pela instituição para o pleno desenvolvimento das competências e habilidades necessárias ao profissional de administração que está sendo formado no curso em questão. Entretanto, saliente-se que por se tratar de uma instituição pública, que depende de recursos públicos para atuar e manter todas as suas atividades, o resultado reflete a realidade apresentada em todo o cenário brasileiro desde o fim da década passada e o início da atual década, onde são apresentadas situações de contingenciamento de gastos em todas as esferas do poder público, principalmente na educação.

\subsection{Satisfação com a instituição}

Já nos quesitos referentes à dimensão nível de satisfação com a instituição como equipamentos, acervos bibliográficos e até mesmo estrutura física, a análise dos dados apresentou os seguintes resultados, a pesquisa obteve dados bastante considerável. Os resultados obtidos estão dispostos na Tabela 6 abaixo:

Tabela 6 - Satisfação com a instituição.

\begin{tabular}{cccccc}
\hline Variável & $\mathbf{1}$ & $\mathbf{2}$ & $\mathbf{3}$ & $\mathbf{4}$ & $\mathbf{5}$ \\
Recursos e equipamentos audiovisuais & $5 \%$ & $14 \%$ & $39 \%$ & $28 \%$ & $15 \%$ \\
Equipamentos e softwares do laboratório de informática & $20 \%$ & $33 \%$ & $34 \%$ & $10 \%$ & $3 \%$ \\
Acervo disponível na biblioteca & $2 \%$ & $22 \%$ & $31 \%$ & $36 \%$ & $9 \%$ \\
\hline
\end{tabular}

Fonte: coleta de dados (2019).

Quanto aos recursos de equipamentos audiovisuais, 28\% dos respondentes afirmaram estar satisfeitos, 39\% se mostraram parciais com os relatos de satisfação devido ao espaço do EITA (Espaço Interativo de Tecnologia e Aprendizagem) que contribui significativamente através do incentivo as atividades práticas, entregando um ambiente voltado para a aplicação de ferramentas administrativas. Resultados contrários foram identificados quando questionados sobre os equipamentos do laboratório de informática, 33\% se mostraram insatisfeitos devido à falta de equipamentos de qualidade que ajudem a executar as atividades desenvolvidas durante as disciplinas. Já o acervo bibliográfico voltado para área de estudo alcançou o percentual de $36 \%$ de satisfação, sendo um contexto de resultados positivos, embora caiba a ressalva da necessidade de melhorias em alguns pontos, como abordados anteriormente.

As análises correspondentes à dimensão relacionada aos níveis de satisfação da infraestrutura física da instituição trouxeram dados positivos com porcentagem de $47 \%$ quanto às estruturas das salas de aulas, com relatos de melhorias como projetores e climatização, assim como a infraestrutura física da instituição com $37 \%$ de satisfação. Desse modo, pode-se 
concluir que o curso em questão, embora limitado por recursos provenientes de forma escassa do órgão público mantenedor, apresenta condições físicas necessárias e satisfatórias para atendimento das demandas, objetivando o melhor desenvolvimento possível das atividades de ensino, pesquisa e extensão.

\section{Conclusões}

O estudo teve como objetivo levantar o nível de satisfação dos discentes do curso de Administração CAMEAM/UERN, o que possibilitou perceber que grande parte das dimensões estudadas apresenta um resultado variante entre parcialmente e totalmente satisfeito, como o relacionamento dos professores, a relevância dos conteúdos das disciplinas, conhecimento dos professores sobre os conteúdos abordados e recursos e equipamentos audiovisuais, concluindo-se, portanto, que existe um bom nível de satisfação entre os discentes do curso em questão.

Entretanto, é importante frisar que a instituição deve ter como objetivo o de desenvolver um olhar crítico para manter essa satisfação, assim como atender as necessidades abordadas como neutras neste estudo, principalmente, as relacionadas à melhoria da estrutura física e acervo didático e equipamentos para o laboratório de informática disponível na instituição, os quais apresentaram os menores índices de satisfação, pois através disso é possível potencializar essa satisfação de forma mais ampla e contribuir ainda mais em todos os aspectos abordados, aspectos esses que contribuem com a qualidade do ensino ofertado pela IES.

Ressalte-se que a presente pesquisa aponta um resultado, apesar do número de respondentes, do nível de satisfação dos discentes, oferecendo uma base sobre o conhecimento da percepção positiva e negativa dos discentes de Administração quanto ao curso, para futuros estudos que possam verticalizar as variáveis aqui apresentadas.

Assim fica aberto o caminho para futuros estudos voltados para a elencar as possíveis variáveis que geram a satisfação acadêmica relacionadas à vida dos estudantes das instituições, sejam elas públicas ou privadas, bem como afetam a percepção individual de qualidade e melhoria ofertadas pelas instituições as quais eles fazem parte.

Por fim, que os resultados apresentados contribuam para a consolidação da satisfação apontada neste trabalho e provoquem a inquietude da busca pela solução das fragilidades identificadas, possibilitando a melhoria contínua das atividades do curso em questão.

\section{Referências}

Andrade. R. O. B., \& Amboni, N. (2004). Gestão de cursos de Administração: metodologias e diretrizes curriculares. Prentice Hall.

Alves, H., Mainardes, E. W., \& Raposo, M. (2010). O marketing no ensino superior: comparativo Brasil-Portugual. R. Adm. FACES Journal. Belo Horizonte. 9(4), 35-64. https://doi.org/10.21714/1984-6975FACES2010V9N4ART190 .

Alyrio, R. D. (2009). Métodos e técnicas de pesquisa em administração. Rio de Janeiro: Fundação CECIERJ.

Bertero, C. O. (2006). Ensino e Pesquisa em Administração. Thomson Learning.

Conselho Federal De Administração. História da Administração. Conselho Federal de Administração. https://cfa.org.br/administracaoadministracao/administracao-historia-da-profissao/

Constituição da República Federativa do Brasil de 1988. http://www.planalto.gov.br/ccivil_03/constituicao/constituicao.htm.

Gil, A. C. (2002). Como elaborar projeto de pesquisa. (4a ed.), Atlas.

Gusmão, J. B. B. (2010). Qualidade da educação no Brasil: consenso e diversidade de significados. Dissertação de Mestrado. Universidade de São Paulo. São Paulo, 180 p.

Instituto Nacional de Estudos e Pesquisas Educacionais Anísio Teixeira (INEP). (2017). Dados do censo da educação superior as universidades brasileiras representam $8 \%$ da rede, mas concentram 53\% das matrículas. <http://portal.inep.gov.br/artigo/-/asset_publisher/B4AQV9zFY7Bv/content/dados-do-censoda-educacao-superior-as-universidades-brasileiras-representam-8-da-rede-mas-concentram-53-das-matriculas/21206 
Research, Society and Development, v.10, n. 1, e4310111472, 2021 (CC BY 4.0) | ISSN 2525-3409 | DOI: http://dx.doi.org/10.33448/rsd-v10i1.11472

Masetto, M. T. (1998). Professor Universitário: Um Profissional Da Educação Na Atividade Docente. In: Masetto, M. T.(Org). (1998). Docência na Universidade. Campinas: Papirus, 1998.

Neves, C. E., \& Martins, C. B. (2014). Ensino superior no Brasil: uma visão abrangente. Repositório IPEA. http://repositorio.ipea.gov.br/bitstream/11058/9061/1/Ensino\%20superior\%20no\%20Brasil.pdf

Neves, A. B., \& Ramos, C. F. (2001). A Imagem Das Instituições De Ensino Superior E Qualidade Do ensino de graduação: a percepção dos acadêmicos do curso de administração. Encontro nacional dos cursos de graduação em administração, 12, São Paulo.

Nicollini, A. (2003). Qual será o futuro das fábricas de administradores? Revista de administração de Empresas. São Paulo. 43(2), 44-54.

Nogueira, M. A. (2004). Universidade, Conhecimento E Opinião. https://www.acessa.com/gramsci/?id=38\&page=visualizar

Pennington, D. C., Zvonkovic, A. M., Wilson, S. L. (1989). Changes in college satisfaction across an academic term. Journal of College Student Development, Baltimore. 30(6), 528-535.

Pinto, V. R. R., \& Motter Junior, M. D. (2012). Uma abordagem histórica sobre o ensino da administração no brasil. Revista do Pensamento Contemporâneo em Administração. Rio de Janeiro. 6(4), 1-28.

Prodanov, C. C., \& Ernani C. F. (2013). Metodologia do trabalho cientifico: métodos e técnicas da pesquisa e do trabalho acadêmico. (2a ed.), Feevale.

Richardson, R. (2007). Pesquisa social: métodos e técnicas. (3a ed.) Atlas.

Schleich, A. L. R. (2006). Integração na educação superior e satisfação acadêmica de estudantes ingressantes e concluintes. (Dissertação de mestrado). Universidade Estadual de Campinas. São Paulo: Campinas, 182 p.

Schreiner, L. A. (2009). Linking Student Satisfaction And Retention. In. Noel-Levitz.

Silva, A. C. da. (2001). Alguns problemas do nosso ensino superior. Estudos Avançados. São Paulo. 15(42), $269-293$.

Soares, A. P. C., Vasconcelos, R. M., \& Almeida, L. S. (2002). Adaptação E Satisfação Na Universidade: Apresentação e validação do Questionário de Satisfação Acadêmica. Contextos e dinâmica da vida acadêmica, Guimarães: Universidade do Minho, 153-156.

Souza, S. A., \& Reinert, J. N. (2010). Avaliação de um curso de ensino superior através da satisfação/insatisfação discente. Revista da Avaliação da Educação Superior. Campinas. 15(1), 159-176.

Stallivieri, L. O sistema de ensino superior do Brasil: características, tendências e perspectivas. Universidade de Caxias do Sul. Rio Grande do Sul: 2006. https://www.ucs.br/site/midia/arquivos/sistema_ensino_superior.pdf . 